Table 1. Regression analysis for variables explaining being on permanent sick leave or disability $(n=1,657)$

\begin{tabular}{|c|c|c|c|c|}
\hline \multirow[b]{2}{*}{ Qualitative variables } & \multicolumn{2}{|c|}{$\begin{array}{c}\text { Univariable logistic } \\
\text { analysis }\end{array}$} & \multicolumn{2}{|c|}{$\begin{array}{c}\text { Multivariable logistic } \\
\text { analysis }\end{array}$} \\
\hline & OR & $95 \% \mathrm{Cl}^{3}$ & OR & $95 \% \mathrm{Cl}^{3}$ \\
\hline Gender $^{1}$ & 1.57 & $1.34,1.83$ & 1.24 & $0.97,1.57$ \\
\hline Educational level $^{2}$ & 1.71 & $1.46,2.00$ & 1.08 & $0.86,1.35$ \\
\hline $\begin{array}{l}\text { Member of a patient organi- } \\
\text { sation. Yes }\end{array}$ & 1.96 & $1.67,2.29$ & 1.54 & $1.23,1.94$ \\
\hline Smoking. Yes & 1.28 & $1.08,1.51$ & 1.22 & $0.96,1.55$ \\
\hline $\begin{array}{l}\text { Difficulty finding job due to } \\
\text { axSpA. Yes }\end{array}$ & 3.71 & $2.89,4.77$ & 2.52 & $1.83,3.47$ \\
\hline $\begin{array}{l}\text { Work choice determined by } \\
\text { axSpA. Yes }\end{array}$ & 1.69 & $1.43,1.99$ & 1.38 & $1.09,1.75$ \\
\hline Anxiety diagnosis. Yes & 1.27 & $1.07,1.51$ & 0.98 & $0.72,1.34$ \\
\hline Depression diagnosis. Yes & 1.58 & $1.33,1.89$ & 1.25 & $0.92,1.69$ \\
\hline Sleep disorder diagnosis. Yes & 1.33 & $1.13,1.56$ & 0.95 & $0.73,1.23$ \\
\hline Quantitative variables & OR & $95 \% \mathrm{Cl}^{3}$ & OR & $95 \% \mathrm{Cl}^{3}$ \\
\hline Age. Years & 1.04 & $1.03,1.04$ & 1.03 & $1.01,1.04$ \\
\hline BASDAI $(0-10)$ & 1.18 & $1.13,1.24$ & 1.06 & $0.98,1.13$ \\
\hline Functional limitation (0-54) & 1.03 & $1.02,1.03$ & 1.01 & $1.00,1.02$ \\
\hline Spinal stiffness (3-12) & 1.25 & $1.20,1.29$ & 1.09 & $1.03,1.15$ \\
\hline Diagnostic delay & 1.01 & $1.01,1.02$ & 0.98 & $0.96,0.99$ \\
\hline Disease duration & 1.04 & $1.03,1.05$ & 1.03 & $1.01,1.04$ \\
\hline
\end{tabular}

${ }^{1}$ Male vs Female; ${ }^{2}$ No university studies vs university studies. ${ }^{3} 95 \% \mathrm{Cl}$ for test $\mathrm{H}_{0}$ : OR=1

Conclusion: One third of patients reported being on permanent sick leave or having a recognised disability. They were more likely to have higher spinal stiffness scores, were older in age, experiencing difficulty finding a job, and belonged to a patient organisation. Increased efforts in relation to early access to effective treatments and the creation of flexible working environments are essential for axSpA patients to continue working and remain active, which benefits their quality of life.

Acknowledgements: This study was supported by Novartis Pharma AG. The authors would like to thank all patients who participated in this study.

Disclosure of Interests: Marco Garrido-Cumbrera: None declared, Christine Bundy Consultant of: Abbvie, Celgene, Janssen, Lilly, Novartis, and Pfizer, Victoria Navarro-Compán Grant/research support from: Abbvie, BMS, Lilly, MSD, Novartis, Pfizer, Roche, and UCB, Laura Christen Employee of: Novartis Pharma AG, Raj Mahapatra: None declared, Souzi Makri: None declared, Carlos Jesús Delgado-Domínguez: None declared, David Gálvez-Ruiz: None declared, Pedro Plazuelo-Ramos: None declared, Denis Poddubnyy Consultant of: Abbvie, BMS, Celgene, Janssen, Lilly, MSD, Novartis, Pfizer, Roche, and UCB, Grant/research support from: Abbvie, MSD, Novartis, and Pfizer.

DOI: 10.1136/annrheumdis-2021-eular.2450

\section{POS0990 FACTORS ASSOCIATED WITH ENGAGING IN PHYSICAL ACTIVITY IN AXIAL SPONDYLOARTHRITIS. RESULTS FROM THE EUROPEAN MAP OF AXIAL SPONDYLOARTHRITIS (EMAS)}

M. Garrido-Cumbrera ${ }^{1}$, D. Poddubnyy ${ }^{2}$, C. Bundy ${ }^{3}$, L. Christen ${ }^{4}$, R. Mahapatra ${ }^{5}$, S. Makri' , C. J. Delgado-Domínguez ${ }^{1}$, D. Gálvez-Ruiz ${ }^{1}$, P. Plazuelo-Ramos ${ }^{7}$, V. Navarro-Compán ${ }^{8}$ on behalf of IMAS working group. ${ }^{1}$ Universidad de Sevilla, Health \& Territory Research (HTR), Seville, Spain; ${ }^{2}$ Charité - Universitätsmedizin Berlin, Rheumatology Department, Berlin, Germany; ${ }^{3}$ Cardiff University, School of Healthcare Sciences, Cardiff, United Kingdom; ${ }^{4}$ Novartis Pharma AG, Patient Engagement, Basel, Switzerland; ${ }^{5}$ Axial Spondyloarthritis International Federation (ASIF), Patient Advocacy, London, United Kingdom; ${ }^{6}$ Cyprus League Against Rheumatism (CYPLAR), Patient Advocacy, Nicosia, Cyprus; ${ }^{7}$ Spanish Federation of Spondyloarthritis Associations (CEADE), Presidency, Madrid, Spain; ${ }^{8}$ Hospital Universitario La Paz, IdiPaz, Madrid, Spain

Background: Physical activity is an essential component in axial spondyloarthritis (axSpA) care, improving physical and mental well-being

Objectives: This analysis aims to identify factors associated with engaging in physical activity among axSpA patients.

Methods: Data from 2,424 unselected patients participating in EMAS $(\mathrm{N}=2,846)$, a cross-sectional study (2017-2018) across 13 European countries, were analysed. Engaging in physical activity was assessed by the following item: "Do you do any physical or sporting activity?" for which participants could report at least 1 physical activity or that they did not do any physical activity. BASDAI (0-10), spinal stiffness (3-12), functional limitation (0-54), and mental health using General Health Questionnaire GHQ-12 (0-12) were assessed. Mann-Whitney and Pearson's $\chi^{2}$ tests were used to analyse relationships between engaging in physical activity and sociodemographic factors, patient-reported outcomes, employment, lifestyle and comorbidities. Univariable and multivariable binary logistic regression were used to analyse variables possibly explaining engagement in physical activity.
Results: Mean age was $43.9 \pm 12.3$ years, $61.3 \%$ were female, $48.1 \%$ had a university degree and $67.9 \%$ were married. $81.8 \%(n=2,329)$ engaged in at least one kind of physical activity. Those physically active were typically male $(85.3 \%$ vs $79.7 \%$ female, $p<0.001)$, university educated $(86.0 \%$ vs $78.0 \%, p<0.001)$, married $(83.1 \%$ vs $79.2 \%$ unmarried, $p=0.046)$, and members of a patient organisation $(86.4 \%$ vs $78.9 \%$ non-member, $\mathrm{p}<0.001) .25 .1 \%$ of obese patients $(n=533)$ did not engage in physical exercise ( $v .16 .6 \%$ not obese, $p<0.001)$. Those not engaging in physical activity reported greater disease activity (6.0 vs 5.4 BASDAI, $p<0.001$ ), functional limitation ( 21.6 vs $20.2, p=0.010$ ), spinal stiffness (8.3 vs $7.6, p<0.001$ ), and poorer mental health (5.9 vs $4.8 \mathrm{GHQ}-12, \mathrm{p}<0.001$ ) Furthermore, $83.9 \%$ of those employed $(n=1,457)$ were physically active, versus $73.7 \%$ unemployed $(n=205 ; p<0.001)$. In the multivariable binary logistic regression, the qualitative variables associated with engaging in physical activity were belonging to a patient organisation $(\mathrm{OR}=1.91)$, not being obese $(\mathrm{OR}=1.58)$, being university educated $(\mathrm{OR}=1.54)$, and being male $(\mathrm{OR}=1.39)$. The quantitative variables associated with engaging in physical activity were lower spinal stiffness $(\mathrm{OR}=0.90)$, better mental health $(\mathrm{OR}=0.96)$, and one-year age increase $(\mathrm{OR}=1.02)$. (Table 1).

Table 1. Regression analysis for variables explaining engagement in physical activity $(n=2,424)$

\begin{tabular}{|c|c|c|c|c|}
\hline \multirow[b]{2}{*}{ Qualitative variables } & \multicolumn{2}{|c|}{$\begin{array}{l}\text { Univariable logistic } \\
\text { analysis }\end{array}$} & \multicolumn{2}{|c|}{$\begin{array}{l}\text { Multivariable logistic } \\
\text { analysis }\end{array}$} \\
\hline & OR & $95 \% \mathrm{Cl}^{7}$ & OR & $95 \% \mathrm{Cl}^{7}$ \\
\hline Gender. Male ${ }^{1}$ & 1.48 & $1.21,1.81$ & 1.39 & $1.06,1.82$ \\
\hline Educational level. University ${ }^{2}$ & 1.73 & $1.42,2.11$ & 1.54 & $1.18,2.00$ \\
\hline Marital Status. Married ${ }^{3}$ & 1.73 & $1.06,1.58$ & 1.18 & $0.91,1.54$ \\
\hline Patient organization. Member ${ }^{4}$ & 1.71) & $1.39,2.10$ & 1.91 & $1.43,2.55$ \\
\hline Body Mass Index. Not Obese ${ }^{5}$ & 1.69 & $1.35,2.12$ & 1.58 & $1.17,2.13$ \\
\hline Employment status. Employed ${ }^{6}$ & 1.28 & $1.06,1.56$ & 1.00 & $0.76,1.32$ \\
\hline Quantitative variables & OR & $95 \% \mathrm{Cl}^{7}$ & OR & $95 \% \mathrm{Cl}^{7}$ \\
\hline Age & 1.01 & $1.00,1.02$ & 1.02 & $1.01,1.03$ \\
\hline BASDAI $(0-10)$ & 0.86 & $0.82,0.91$ & 0.96 & $0.89,1.04$ \\
\hline GHQ-12 (0-12) & 0.94 & $0.92,0.96$ & 0.96 & $0.93,0.99$ \\
\hline Functional Limitation (0-54) & 0.99 & $0.99,1.00$ & 1.00 & $0.99,1.01$ \\
\hline Spinal Stiffness (3-12) & 0.90 & $0.86,0.94$ & 0.90 & $0.84,0.95$ \\
\hline Proportion of life with axSpA (0-1) & 2.83 & $1.50,5.35$ & 2.00 & $0.91,4.39$ \\
\hline
\end{tabular}

${ }^{1}$ Male vs Female; ${ }^{2}$ University vs no university; ${ }^{3}$ Married vs unmarried; ${ }^{4}$ Member vs not; ${ }^{5}$ No obese (underweight, normal and overweight) vs obese; ${ }^{6}$ Employed vs not (unemployed, sick leave, retirement, housework and student). ${ }^{7} 95 \% \mathrm{Cl}$ for test $\mathrm{H}_{0}$ : OR=1

Conclusion: These results show that increasing age, being male, university educated, member of a patient organisation, not obese, having lower spinal stiffness, and better mental health increase the probability of engaging in physical activity. Physical activity is an important part of axSpA care and patient organizations play a critical role in enhancing access to and participation in physical activity. Acknowledgements: This study was supported by Novartis Pharma AG. The authors would like to thank all patients who participated in the study.

Disclosure of Interests: Marco Garrido-Cumbrera: None declared, Denis Poddubnyy Consultant of: Abbvie, BMS, Celgene, Janssen, Lilly, MSD, Novartis, Pfizer, Roche, and UCB., Grant/research support from: Abbvie, MSD, Novartis, and Pfizer, Christine Bundy Consultant of: Abbvie, Celgene, Janssen, Lilly, Novartis, and Pfizer, Laura Christen Employee of: Novartis Pharma AG, Raj Mahapatra: None declared, Souzi Makri: None declared, Carlos Jesús Delgado-Domínguez: None declared, David Gálvez-Ruiz: None declared, Pedro Plazuelo-Ramos: None declared, Victoria Navarro-Compán Grant/research support from: Abbvie, BMS, Lilly, MSD, Novartis, Pfizer, Roche, and UCB. DOI: 10.1136/annrheumdis-2021-eular.2469

\section{POS0991 THE IMPACT OF AXIAL SPONDYLOARTHRITIS ON PATIENTS' SEXUAL LIFE: RESULTS FROM THE SPANISH ATLAS}

M. Garrido-Cumbrera ${ }^{1}$, J. Gratacos-Masmitja ${ }^{2}$, E. Collantes-Estevez ${ }^{3}$, P. ZarcoMontejo $^{4}$, C. Sastré ${ }^{5}$, S. Sanz-Gómez ${ }^{1}$, P. Plazuelo-Ramos ${ }^{6}$, V. NavarroCompán ${ }^{7}$ on behalf of Atlas working group. ${ }^{1}$ Universidad de Sevilla, Health \& Territory Research (HTR), Seville, Spain; ${ }^{2}$ Hospital Universitaria Parc Taulí, Rheumatology Department, Barcelona, Spain: ${ }^{3}$ Reina Sofia University Hospital, Rheumatology Department, Cordova, Spain; ${ }^{4}$ Hospital Universitario Fundación Alcorcón, Rheumatology Department, Madrid, Spain; ${ }^{5}$ Novartis Farmacéutica Spain, Immunology, Hepatology and Dermatology, Barcelona, Spain; ${ }^{6}$ Spanish Federation of Spondyloarthritis Associations (CEADE), Patient Advocacy, Madrid, Spain; ${ }^{7}$ Hospital Universitario La Paz, IdiPaz, Madrid, Spain

Background: Axial Spondyloarthritis (axSpA) can impact patients' sexual life. Objectives: The aim is to assess the prevalence of functional limitation in sexual activity in axSpA patients in Spain and its associated factors. 
Methods: Data from an online survey of 680 unselected axSpA patients pertaining to the Atlas of Axial Spondyloarthritis in Spain were collected. Functional limitation in intimate relations was assessed through a 3-point Likert scale (low, medium, and high) and the sample was divided into 1) low-medium and 2) high. Mann-Whitney and $\chi^{2}$ tests were used to analyse relations between sociodemographic, employment, lifestyle, patient-reported outcomes, and comorbidities with respect to functional limitation in intimate relations. Univariate and multivariate binary logistic regression was used to analyse its associated factors.

Results: 605 axSpA patients were included: the mean age was 45.5 years, $51.4 \%$ were female, $38.3 \%$ had a university degree, and $70.7 \%$ were married. A total of $57.7 \%, 28.9 \%$, and $13.4 \%$ participants presented high, medium, and low limitation in intimate relations, respectively. Patient with high functional limitation in intimate relations were younger ( 44.6 vs $46.7, p=0.032$ ), female $(67.2 \%$ vs $47.6 \%$ of male, $p<0.001)$, did not belong to a patient organisation $(62.7 \%$ vs $51.5 \%$ of members, $p=0.006)$, were on sick leave $(73.3 \%$ vs $51.9 \%$ of employed, $\mathrm{p}<0.001)$ and smoked more $(67.3 \%$ vs $52.6 \%, \mathrm{p}<0.001)$. The high limitation group presented higher disease activity (6.3 vs 4.9$)$, functional limitation (48.2 vs 34.4 ) and spinal stiffness ( 7.9 vs 6.9 , all $p<0.001)$, worse mental health ( 7.0 vs $4.1, p<0.001)$, longer diagnostic delay (9.2 vs $7.6, p=0.019)$, and more comorbidities such as anxiety (73.3\% vs $53.2 \%)$, depression $(80.0 \%$ vs $53.3 \%$ ) and sleep disorders $(70.9 \%$ vs $53.9 \%$, all $p<0.001)$. In addition, $80.3 \%$ of patients with decreased frequency of intimate relations presented high functional limitation in intimate relations (vs 10.0\% with more frequency) and $81.4 \%$ had experienced a worsening relationship with their spouse (vs $55.6 \%$ with better relation, all $p<0.001)$. In the multivariate binary logistic regression, the qualitative factors associated with high functional limitation in intimate relations were a reduction in the frequency of intimate relations $(O R=18.66)$ and smoking $(\mathrm{OR}=2.89)$, while the quantitative factor associated with high functional limitation in the intimate relation was higher overall functional limitation $(B=0.292 ;$ Table 1).

Table 1. Logistic regression to analyse factor associated with high functional limitation in intimate relation $(\mathrm{N}=302)$

\begin{tabular}{|c|c|c|c|c|}
\hline & \multicolumn{2}{|c|}{$\begin{array}{l}\text { Univariate logistic } \\
\text { analysis }\end{array}$} & \multicolumn{2}{|c|}{$\begin{array}{l}\text { Multivariate logistic } \\
\text { analysis }\end{array}$} \\
\hline & OR & p-value ${ }^{1}$ & OR & p-value ${ }^{1}$ \\
\hline \multicolumn{5}{|l|}{ Qualitative factors } \\
\hline Gender. Female & 2.254 & $<0.001$ & 1.311 & 0.569 \\
\hline Patient Organization. Member & 0.632 & 0.006 & 0.515 & 0.171 \\
\hline Employment. Sick leave & 2.354 & $<0.001$ & 1.060 & 0.910 \\
\hline Smoking. Yes & 1.852 & 0.001 & 2.885 & 0.020 \\
\hline Anxiety diagnosis. Yes & 2.420 & $<0.001$ & 0.569 & 0.306 \\
\hline Depression diagnosis. Yes & 3.509 & $<0.001$ & 1.665 & 0.408 \\
\hline Sleep disorder diagnosis. Yes & 2.081 & 0.001 & 0.625 & 0.381 \\
\hline $\begin{array}{l}\text { Frequency of intimate relation. Less than } \\
\text { before vs same or more than before }\end{array}$ & 12.605 & $<0.001$ & 18.655 & $<0.001$ \\
\hline Relation with spouse. Worse than before & 5.480 & $<0.001$ & 1.256 & 0.636 \\
\hline Quantitative factors & B & p-value ${ }^{2}$ & B & p-value ${ }^{2}$ \\
\hline Age & -0.018 & 0.021 & 0.010 & 0.718 \\
\hline BASDAI $(0-10)$ & 0.398 & $<0.001$ & -0.155 & 0.284 \\
\hline GHQ-12 (0-12) & 0.154 & $<0.001$ & 0.003 & 0.952 \\
\hline Functional Limitation (0-54) & 0.237 & $<0.001$ & 0.292 & $<0.001$ \\
\hline Spinal Stiffness (3-12) & 0.131 & $<0.001$ & -0.116 & 0.226 \\
\hline Diagnostic Delay & 0.030 & 0.013 & 0.020 & 0.474 \\
\hline
\end{tabular}

${ }^{1} \mathrm{p}$-value for test $\mathrm{H}_{0}: \mathrm{OR}=1^{2} \mathrm{p}$-value for test $\mathrm{H}_{0}: \mathrm{B}=0$

Conclusion: More than half of patients with axSpA in Spain presented high functional limitation in intimate relations, who more likely presented decreased frequency of relations. This may indicate that avoidance of sexual encounters is a common coping mechanism for the functional limitation accompanying this disease. Healthcare providers can play a key role in the sexual health of axSpA patients by improving patient-physician communication and raising awareness about the benefits of counselling on a healthy sexual life.

Acknowledgements: This study was supported by Novartis Spain. The authors would like to thank all patients who participated in this study.

Disclosure of Interests: Marco Garrido-Cumbrera: None declared, Jordi Gratacos-Masmitja Grant/research support from: Abbvie, BMS, Lilly, MSD, Novartis, Pfizer, Roche, and UCB, Eduardo Collantes-Estevez Grant/ research support from: Abbvie, BMS, Lilly, MSD, Novartis, Pfizer, Roche, and UCB, Pedro Zarco-Montejo: None declared, Carlos Sastré Employee of: Novartis Farmacéutica Spain, Sergio Sanz-Gómez: None declared, Pedro Plazuelo-Ramos: None declared, Victoria Navarro-Compán Grant/ research support from: Abbvie, BMS, Lilly, MSD, Novartis, Pfizer, Roche, and UCB.

DOI: 10.1136/annrheumdis-2021-eular.2491

\section{\begin{tabular}{|l|l}
\hline POS0992 & PREVALENCE AND ASSOCIATED FACTORS OF
\end{tabular} SLEEP DISORDERS IN PATIENTS WITH AXIAL SPONDYLOARTHRITIS. RESULTS FROM THE SPANISH ATLAS}

M. Garrido-Cumbrera ${ }^{1}$, V. Navarro-Compán ${ }^{2}$, E. Collantes-Estevez ${ }^{3}$, P. ZarcoMontejo $^{4}$, S. Sanz-Gómez ${ }^{1}$, C. Sastré ${ }^{5}$, P. Plazuelo-Ramos ${ }^{6}$, J. GratacosMasmitja ${ }^{7}$ on behalf of Atlas working group. ${ }^{1}$ Universidad de Sevilla, Health \& Territory Research (HTR), Seville, Spain; ${ }^{2}$ Hospital Universitario La Paz, IdiPaz, Madrid, Spain; ${ }^{3}$ Reina Sofia University Hospital, Rheumatology Department, Cordova, Spain; ${ }^{4}$ Hospital Universitario Fundación Alcorcón, Rheumatology Department, Madrid, Spain; ${ }^{5}$ Novartis Farmacéutica Spain, Immunology, Hepatology and Dermatology, Barcelona, Spain; ${ }^{6}$ Spanish Federation of Spondyloarthritis Associations (CEADE), Patient Advocacy, Madrid, Spain; ${ }^{7}$ Hospital Universitaria Parc Taulí, Rheumatology Department, Barcelona, Spain

Background: Sleep is an essential aspect of health that is commonly disrupted in patients with axial spondyloarthritis (axSpA).

Objectives: This analysis aims to assess the prevalence and associated factors of sleep disorders in a large sample of axSpA patients.

Methods: In 2016, a sample of 680 unselected patients with axSpA participated in the Atlas of Axial Spondyloarthritis in Spain through an online survey. The sample was divided into: 1) Patients with sleep disorders and 2) Patients without sleep disorders. Disease activity through BASDAI (0-10), spinal stiffness (3-12), functional limitation (0-54) and, mental health through a 12-item General Health Questionnaire GHQ-12 (0-12) were assessed. The Mann-Whitney and Pearson's chi-square tests were used to analyse possible relationships between independent sociodemographic characteristics, employment, lifestyle, patient-reported outcomes and comorbidity variables with sleep disorders. Univariate and multivariate binary logistic regression was used to determine the possible association of the independent variables on sleep disorders. Results: Mean age was 45.7 years, $52.5 \%$ female, $36.9 \%$ had a university degree, and $71.5 \%$ were married. The prevalence of sleep disorders was $19.7 \%$. Those who reported sleep disorders presented higher disease activity (6.3 vs $5.4, p<0.001)$, worse mental health ( 7.7 vs $5.0, p<0.001)$, greater functional limitation ( 45.7 vs $41.4, p<0.001$ ), greater spinal stiffness ( 8.0 vs $7.3, p=0.008$ ), and longer diagnostic delay $(10.5$ vs $7.9, p=0.021) .29 .9 \%$ of the patients on sick leave had sleep disorders, compared to only $15.4 \%$ of employees $(p=0.013)$. In addition, $23.0 \%$ of those who were physically active had sleep disorders compared to only $7.1 \%$ of those not physically active $(p<0.001)$. Sleep disorders were more prevalent in patients with other comorbidities such as anxiety $(60.0 \%$ vs $9.7 \%$, w/o anxiety, $\mathrm{p}<0.001)$ and depression $(66.0 \%$ vs $11.7 \%$ w/o depression, $\mathrm{p}<0.001)$. In the multivariate binary logistic regression, depression $(O R=3.89)$, anxiety $(O R=3.84)$, and a longer diagnostic delay $(B=0.034)$ remained significantly associated with sleep disorders. Excluding mental comorbidity parameters from the model, physical activity $(O R=3.52)$ and disease activity $(B=0.175)$ remained significantly associated with sleep disorders (Table 1).

Table 1. Logistic regression to analyses factor associated with sleep disorders $(\mathrm{N}=366)$

\begin{tabular}{|c|c|c|c|c|c|c|}
\hline & \multicolumn{2}{|c|}{$\begin{array}{l}\text { Univariate logistic } \\
\text { analysis }\end{array}$} & \multicolumn{2}{|c|}{$\begin{array}{l}\text { Multivariate logis- } \\
\text { tic analysis }\end{array}$} & \multicolumn{2}{|c|}{$\begin{array}{l}\text { Multivariate } \\
\text { logistic analysis }\end{array}$} \\
\hline & OR & p-value ${ }^{1}$ & OR & $p$-value ${ }^{1}$ & OR & $p$-value ${ }^{1}$ \\
\hline \multicolumn{7}{|l|}{ Qualitative factors } \\
\hline Employment. Sick leave & 1.937 & 0.003 & 1.554 & 0.180 & 1.540 & 0.131 \\
\hline Physical activity. Yes & 3.914 & $<0.001$ & 2.410 & 0.196 & 3.516 & 0.048 \\
\hline Anxiety diagnosis & 13.925 & $<0.001$ & 3.840 & $<0.001$ & - & -- \\
\hline Depression diagnosis & 14.616 & $<0.001$ & 3.886 & $<0.001$ & -- & -- \\
\hline Quantitative factors & B & $p$-value ${ }^{2}$ & B & p-value ${ }^{2}$ & B & p-value ${ }^{2}$ \\
\hline BASDAI (0-10) & 0.238 & $<0.001$ & 0.036 & 0.673 & 0.175 & 0.015 \\
\hline GHQ-12 & 0.141 & $<0.001$ & 0.045 & 0.204 & -- & -- \\
\hline Functional Limitation (0-54) & 0.049 & $<0.001$ & -0.011 & 0.560 & 0.022 & 0.166 \\
\hline Spinal Stiffness (3-12) & 0.104 & 0.008 & 0.016 & 0.775 & 0.020 & 0.683 \\
\hline Diagnostic Delay & 0.041 & 0.001 & 0.034 & 0.044 & 0.025 & 0.083 \\
\hline
\end{tabular}

${ }^{*}$ Excluding mental health factors. ${ }^{1} \mathrm{p}$-value for test $\mathrm{H}_{0}: \mathrm{OR}=1{ }^{2} \mathrm{p}$-value for test $\mathrm{H}_{0}: \mathrm{B}=0$

Conclusion: One of five patients with axSpA reported sleep disorders. The presence of mental comorbidities such as anxiety and depression increases the likelihood of sleep disorders. Moreover, physical activity and disease activity also seem to increase the probability on sleep disorders. Referral to mental health specialists together with optimal healthcare management should be key for the reduction of sleep disorders in axSpA.

Acknowledgements: This study was supported by Novartis Spain. The authors would like to thank all patients who participated in this study.

Disclosure of Interests: Marco Garrido-Cumbrera: None declared, Victoria Navarro-Compán Grant/research support from: Abbvie, BMS, Lilly, MSD, Novartis, Pfizer, Roche, and UCB, Eduardo Collantes-Estevez Grant/research support from: Abbvie, BMS, Lilly, MSD, Novartis, Pfizer, Roche, and UCB, Pedro Zarco-Montejo: None declared, Sergio Sanz-Gómez: None declared, Carlos 